\title{
GROWTH MECHANISMS OF SINGLE-WALL CARBON NANOTUBES IN A CHEMICAL VAPOR DEPOSITION (CVD) PROCESS ON Fe/Mo-AI CATALYST
}

\author{
Le Van Thang \\ University of Technology, VNUHCM \\ (Manuscript Received on April 5 ${ }^{\text {th }}, 2012$, Manuscript Revised May 15 ${ }^{\text {th }}$, 2013)
}

\begin{abstract}
The formation mechanisms involved in the growth of single-walled carbon nanotubes (SWNTS) by chemical vapor deposition (CVD) was studied. Transmission electron microscopy (TEM) was used to analyze the encapsulated metal catalyst particles found within the tubes, and the dimensions and location of these particles was determined. SWNTs were found to have encapsulated particles in the end of tubes, with large length to diameter ratios. As a result of these observations, we concluded that SWNTs are formed via an open-ended, base-growth mechanism (VLS mechanism). Additionally, we have demonstrated the formation of two kinds of bundles of SWNTs (Parallel bundles and as-rope bundles). SWNTs grown with thermal CVD on Fe/Mo-Al catalyst did not contain similar elongated particles or particles along the middle of the tubes, indicating that these new growth mechanisms are only applicable in the case of tubes grown via vapor phase CVD growth methods.
\end{abstract}

Keywords: Carbon nanotubes, base-growth mechanism, Transmission electron microscopy

\section{INTRODUCTION}

Since their discovery nearly twenty years ago, single wall carbon nanotubes (SWNT) have been the focus of numerous investigations because of their unique and superior electronic, chemical, physical and mechanical properties, representing the ultimate carbon fiber [1-8].

But one major challenge is to control the growth of SWNTs, in particular concerning their diameter and helicity. To achieve a controllable growth of the CNTs with high quality, understanding of their growth mechanism is of importance, which still remains an open question [1]. Naturally, the growth mechanism of nanotubes is not well understood. It may be different depending on which method is used.

It is known that the arc-discharge and laser-ablation method lead to growth of MWNT without using metal catalyst whereas for carbon nanotubes to be synthesized with the CVD method, the catalyst particles are necessary. In contrast, for the growth of SWNTs, catalysts play an important role for all three methods mentioned above [1, 6-8]. Carbon nanotubes produced using the CVD method exhibit high purity, high yield, and perfect orientation. According to the different growth modes of CNTs by CVD, scientists have proposed several kinds of growth

\section{Trang 72}


TÄ̈ CHÍ PHAU் TRIEÅ KH\&CN, TAR̈ 16, SOÁK1- 2013

mechanisms: base growth mechanism, tips growth mechanism [2, 3], Yarmulke growth mechanism [9] etc. Dai et al. and Kukovitsky et al. [10] have put forward vapor-liquid-solid (VLS) mechanism. In this mechanism, liquid catalytic particles at high temperature accepted carbon atoms from the vapor, causing the liquid to become supersaturated, the supersaturated carbon atoms then deposited to form CNTs. The liquid catalytic particles acted as the medium for transport from the vapor to the crystal and the CNTs grew by the deposition of supersaturated carbon atoms. In VLS model, molecular decomposition and carbon solution are deposited at one side of the catalytic particle. Carbon diffuses from the side where it has been decomposed to another side where it is precipitated from solution. The metal-support interactions are found to play a determinant role for the growth mechanism.

In the present work SWNTs have been synthesized by the catalytic decomposition of methane, over $\mathrm{Fe}-\mathrm{Mo}-\mathrm{Al}$ catalyst in a tube furnace, which allows continuous control of the CNT synthesis in real time. The properties of CNTs have been studied using SEM, RAMAN and TEM. Based on our TEM results, a growth mechanism is described.

\section{EXPERIMENTAL}

The nanotubes were grown by a thermal CVD of methane at atmospheric pressure.

\subsection{Materials}

Silicon (100) wafer with surface oxide layer of thickness $1 \mu \mathrm{m}$ was used as the substrate. All materials used in experiments are research grade materials purchased from different suppliers. $\mathrm{Fe}\left(\mathrm{NO}_{3}\right)_{3} \cdot 9 \mathrm{H}_{2} \mathrm{O}$, and $\mathrm{MoO}_{2}$ (acetyl acetone) $)_{2}$ were purchased from Sigma Aldrich chemicals. Oxide C alumina obtained from Degussa Inc. Air product provided high-purity methane and hydrogen.

\subsection{Catalyst preparation}

In the initial methane CVD method, we used an $\mathrm{Fe}\left(\mathrm{NO}_{3}\right)_{3} \cdot 9 \mathrm{H}_{2} \mathrm{O}$, $\mathrm{MoO}_{2}$ (acetylacetone) $)_{2}$, and $30 \mathrm{mg}$ of alumina nanoparticles catalyst prepared by impregnation in methanol. $40 \mathrm{mg}$ of $\mathrm{Fe}\left(\mathrm{NO}_{3}\right)_{3} \cdot 9 \mathrm{H}_{2} \mathrm{O}, \quad 3 \quad \mathrm{mg}$ of $\mathrm{MoO}_{2}$ (acetylacetone) $)_{2}$, and $30 \mathrm{mg}$ of Alumina nanoparticles are mixed in $30 \mathrm{ml}$ of methanol and sonicated for $\sim 1 / 2 \mathrm{hr}$. Then, the liquid catalyst is deposited onto the substrate by micropipette.

\subsection{Carbon nanotubes growth}

Catalyst materials were deposited onto the $\mathrm{Si} / \mathrm{SiO}_{2}$ substrate were calcined in $\mathrm{Ar}$ environment at $400^{\circ} \mathrm{C}$ for 15 minutes, cooled to room temperature, and put it inside a 3 inches diameters quartz tube mounted in an electric tube furnace. The quartz was heated from room temperature to $900^{\circ} \mathrm{C}$ under Ar flow at a flow rate of $1000 \mathrm{sccm}$. The reaction began when adding $\mathrm{H}_{2}: \mathrm{CH}_{4}(250: 1000$ sccm)for the desired reaction time (14 mins). The flow was then switched to Ar and the furnace was cooled to room temperature. 


\subsection{Characterizations}

SWNT samples were fully characterized using SEM, TEM and Raman spectroscopy.

The growth mechanism of SWNTs in the methane CVD process was determined systematic by TEM imaging of nanotube ends. Using TEM grids as substrates for the growth of carbon nanotubes is a very simple approach. The TEM grids are thin metal foils with punched holes. The grids have a diameter of $3.05 \mathrm{~mm}$ and a thickness of 12 to $15 \mu \mathrm{m}$. The melting point of the grids' metals is higher than $1000^{\circ} \mathrm{C}$ which means that the grids should withstand the growth process.

\section{RESULTS AND DISCUSSION}

\subsection{Catalyst on the copper grid}

The suspension catalyst was covered on thecopper grid by the micropipette and characterized with TEM.

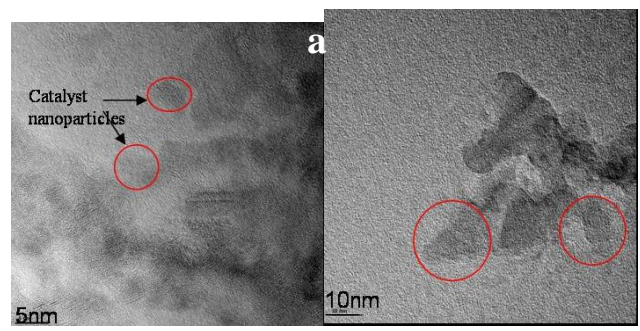

Figure 1. TEM images of catalyst on the copper grid

TEM images shown catalyst particles with different sizes. Diameter of catalytic grains in fig. 1a was smaller than that of alumina particles $(13 \mathrm{~nm})$. So, these particles are the grains of active catalyst.

\subsection{Carbon nanotube characterization}

Figure 2 is micrograph of the nanotubes growth sample prepared in our process. However, those nanotubes are multi-walled or single-walled tubes were firstly verified Raman spectroscopy. This technique is useful in distinguishing between the MWNTs and SWNTs because the spectra of them contain special vibration modes.

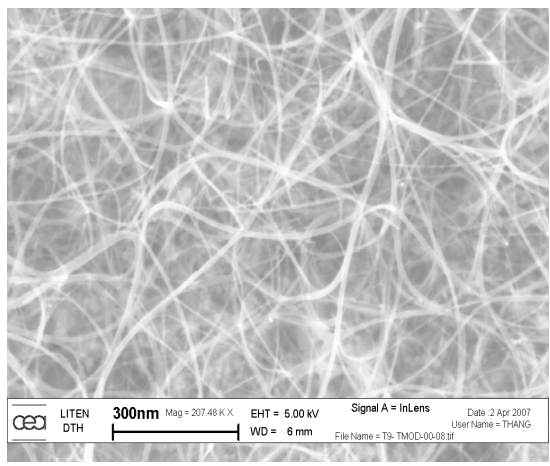

Figure 2. SEM image of CNTs production

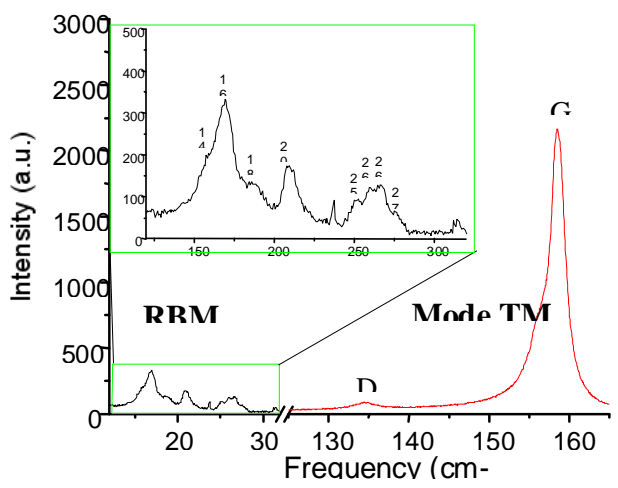

Figure 3. Raman spectroscopy of CNTs products

We were characterized SWNTs properties by a Raman microscope system (YVON) at an excitation wavelength of $514.5 \mathrm{~nm}$. 
The diameter (d) is determined by measuring the RBM frequency and applying the formula:

$$
v \mathrm{RBM}=224 / \mathrm{d}(\mathrm{nm})
$$

Raman spectra show several RBM signals, suggesting that the grown SWNTs are bundles or individuals nanotubes. The frequency range for the observed RBM signals (120-300 $\mathrm{cm}^{-1}$ ) corresponds to tube diameters from 0.8 to 2 nm.

In the high-frequency range of the Raman spectra, we observe a prominent G-band ( $\left.1590 \mathrm{~cm}^{-1}\right)$ and the weak D-band $\left(\sim 1350 \mathrm{~cm}^{-1}\right)$. As it is well known, the G-band intensity is approximately proportional to density of SWNTs. The D-band is related to the structural disorder of $\mathrm{sp}^{2}$ bonded nanocrystalline and/or amorphous carbon species. Its low intensity is indicating that very few defects are presents in these SWNTs. The quality of the tubes can be also identified using the very low ratio between the D-band and G-band (0.1 -0.05).

\subsection{TEM images of carbon nanotube on the molybdenum grid}

The results of the experiments with TEM grid can be summarized as follow:

The TEM pictures are taken at the Center for Nanoscale characterization, MINATEC/LETI. Long CNTs can be seen in the figure 4 that were produced by CVD process at $900^{\circ} \mathrm{C}$. The length of this particular CNT is about few ten of micrometers.
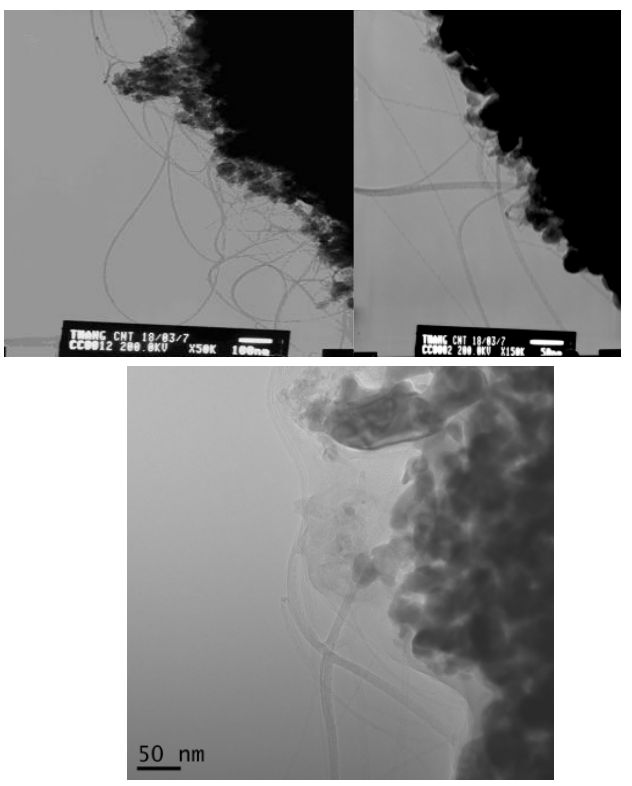

Figure 4. TEM images of as-grown CNTs on Molybdenum grid

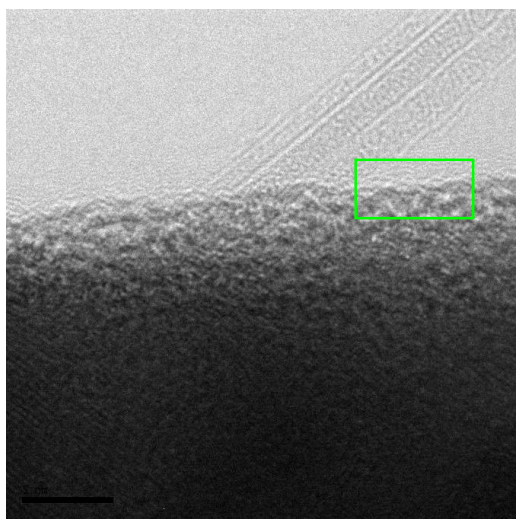

Figure 5. TEM images of Bundle SWNTs

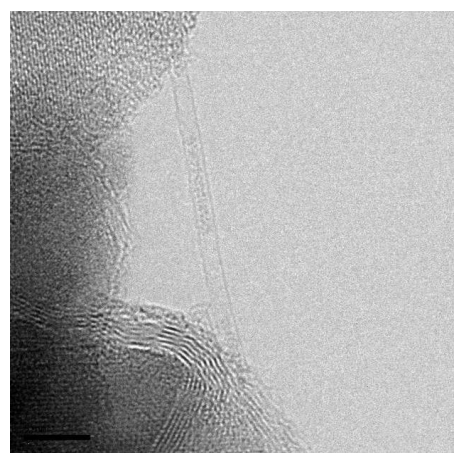

Figure 6. TEM images of individual SWNTs 
Amorphous carbon structures are also observed together with the CNTs (inset in fig 5)

TEM pictures show the bundles (fig. 5) and individual (fig. 6) single-walled carbon nanotubes. These nanotubes have diameter of around $1.4 \mathrm{~nm}$. The observed bundle SWNT includes some parallel tubes with diameter in the range of 1.3-1.6 nm.

Graphene layers covering the catalyst nanoparticles are seen together with catalyst particles in fig 6 .

In summary, TEM studies of carbon nanotubes demonstrated different single walled carbon nanotubes (the individual and bundles of SWNTs). In some of images, catalyst particles, on which the carbon nanotubes were grown, were also observed. In our case, most of the individual SWNTs have diameter smaller than $2 \mathrm{~nm}$. However, there are also some other nano-objects produced in the system such as amorphous carbon or graphene layers. The TEM results also confirmed that the MWNT and DWNT didn't grow on our process.

\subsection{The growth mechanism of CNT}

With TEM images, we found that the bottoms of nanotubes are attached by small catalyst particles. In all cases, it is found that the bottoms with catalyst nanoparticles are always anchored on the alumina support (red arrows in fig 7).
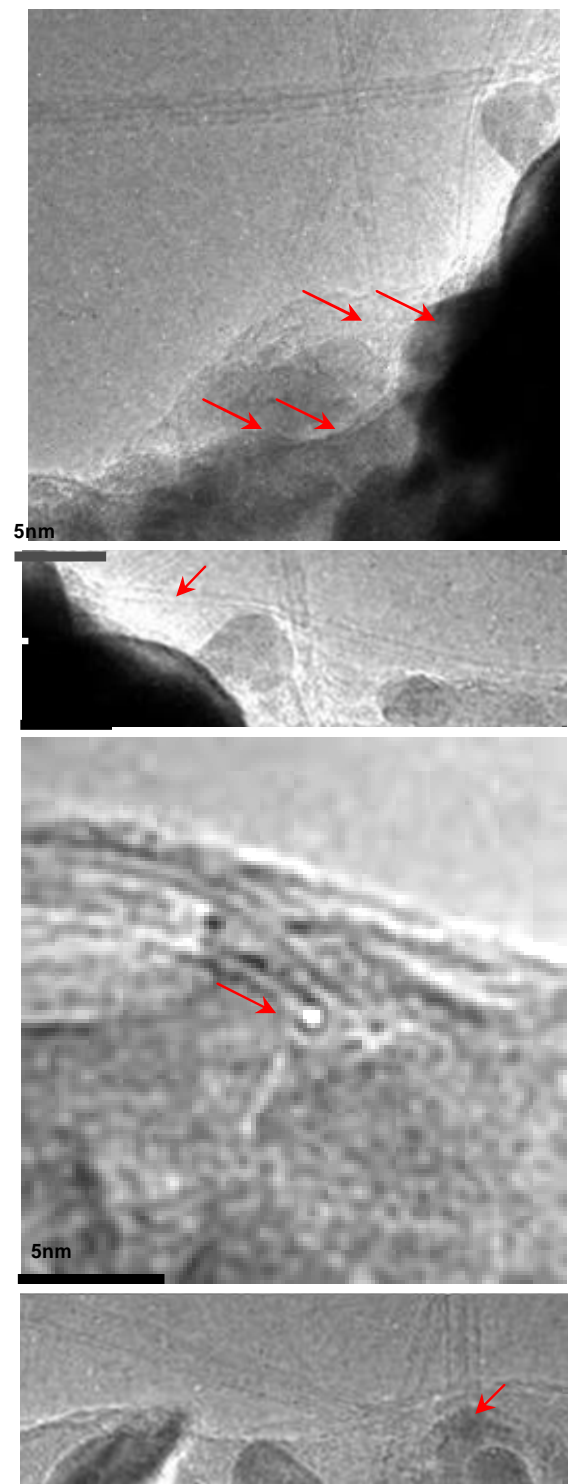

Figure 7. A typical HRTEM images of the tips of individual SWNTs synthesized on $\mathrm{Fe}_{2} \mathrm{O}_{3}-\mathrm{MoO}_{3} /$

$$
\mathrm{Al}_{2} \mathrm{O}_{3} \text { catalyst }
$$




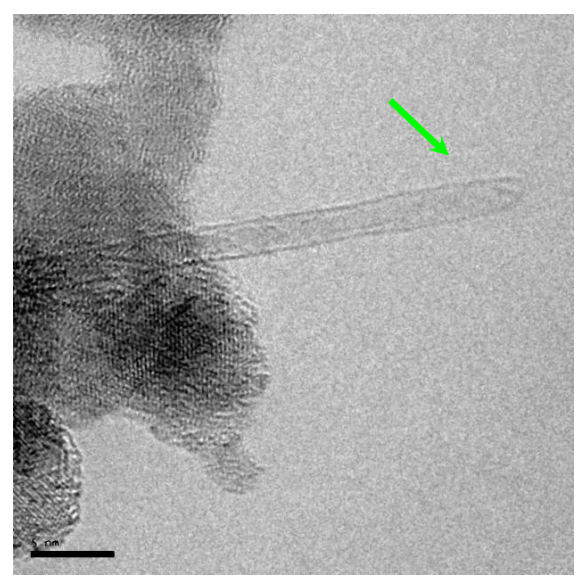

Figure 8. TEM images of SWNTs without catalytic particles at the top

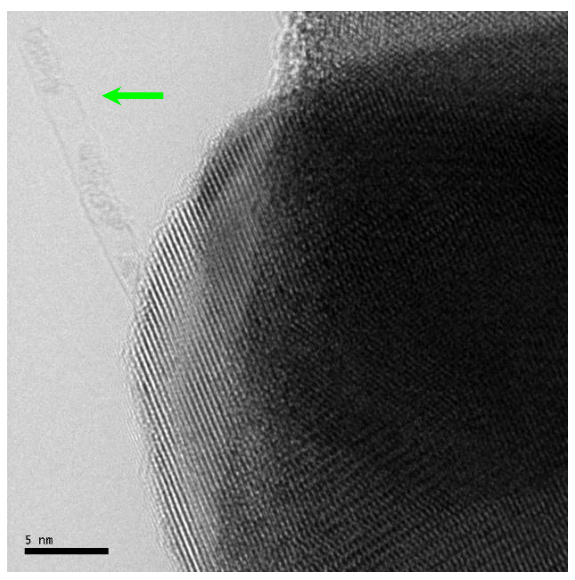

Figure 9. TEM images of the top of SWNTs

Figure 8 and 9 show that the top of the tubes can extend out of the grid. Importantly, we have not seen a SWNT extending out of grid with the catalyst nanoparticles on the top (bright green arrows in figure 8 and 9).

Based on the states of the nanotubes ends and the TEM results, we propose that SWNTs grow via the "base-growth" model. And to explain the growth mechanism of carbon nanotubes in methane CVD process, we propose the vapor-liquid-solid (VLS) model which was introduced to explain the growth of carbon nanotubes.

In our "base-growth" model, at the early stage of the CVD reaction, carbon atoms catalytically decomposed from the methane are absorbed onto the nanoparticles surface, forming carbon-active catalyst liquid-state. As discussed above, this liquid-state is reached because of the active catalyst particles have nanometre sizes: leading to reduced melting points. If the methane supply to the process continues, a super saturation point of carbon in liquid state is reached, carbon precipitates out from the nanoparticles surface. This leads to the growth of single-walled carbon nanotubes. The growth stops when the methane becomes insufficient or the active catalyst particle is poisoned by reaction (fig. 10).

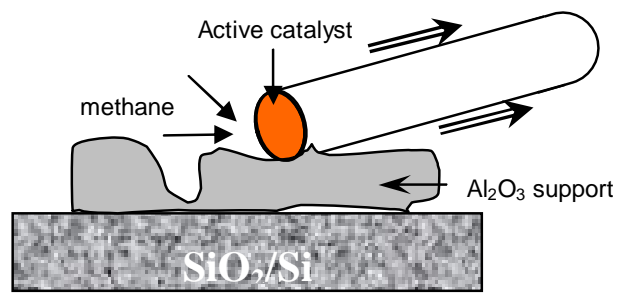

Figure 10. A schematic growth mechanism of individual SWNTs from catalyst nanoparticles

For bundles of single-walled carbon nanotubes, the growth mechanism is the same as with individual SWNTs. 


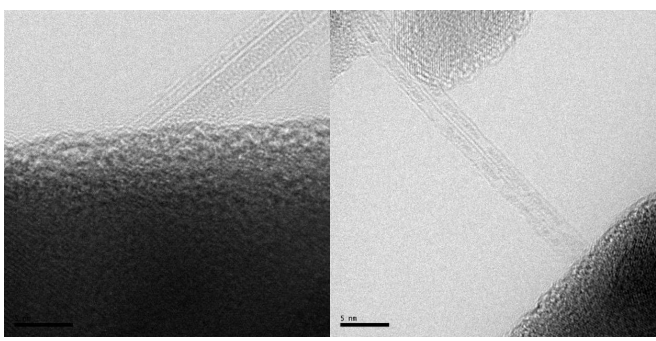

Figure 11. Some parallel SWNTs in bundles

In our SWNTs products, we obtain two kinds of bundle:

- Parallel SWNTs in bundles (fig 11)

- As-rope SWNTs in bundles (fig 12): some individual nanotubes are twisted into a rope

These bundles of SWNTs products can explain by the important role of the fume and porous alumina support. As already stated, the fume alumina material $\left(\gamma-\mathrm{Al}_{2} \mathrm{O}_{3}\right)$ are anisotropic since they contain crystal edges, corners, and hydroxyl groups (-OH).

So, the active catalyst particles form the strongly interaction with the support's surface. This phenomenon allows to the formation of numerous of active centers on the support's surface. These active centers are very close together. This leads to growth of the bundles of nanotubes. The kinds of bundles of SWNT depend on the position of active catalyst and the growth direction (fig. 13)
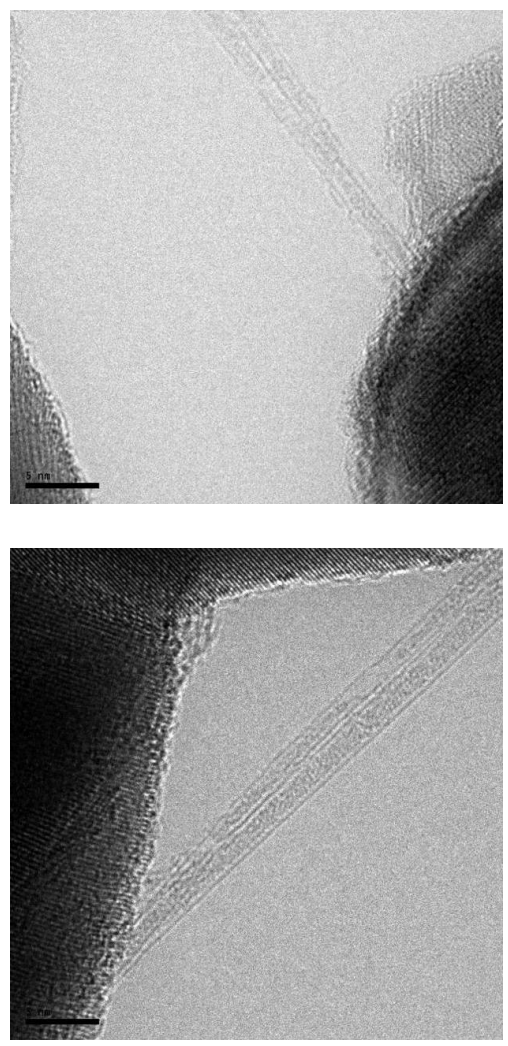

Figure 12. TEM images of as-rope SWNTs

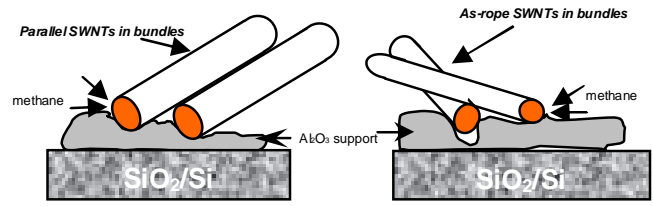

Figure 13. Growth mechanism of bundles SWNTs during CVD process

\section{CONCLUSION}

The production of high-quality of singlewalled carbon nanotubes by catalyst CVD method has been achieved. The producedSWNTs are a mixture of the semiconducting and metallic SWNTs with the diameters in the range of 0.8-1.8 nm. However, the experiment results also confirmed that our products 
TAP̈ CHÍ PHAÙ TRIEÂ KH\&CN, TA:̈ 16, SOÁK1- 2013

contained impurities (amorphous carbon, nanotubes in methane CVD process. Besides, graphite layer) we have demonstrated the formation of two

We have suggested the "base-growth" mechanism of individual single-walled carbon kinds of bundles of SWNTs (Parallel bundles and as-rope bundles).

\title{
NGHIÊN CÚU CƠ CHẾ PHÁT TRIỂN CỦAỐNG NANO CARBON ĐƠN THÀNH TỔNG HỢP TRÊN XÚC TÁC Fe/Mo-Al BẰNG THIÊT BỊ NGUUNG TỤ HƠI HOÁ HỌC
}

\author{
Lê Văn Thăng \\ Trường Đại học Bách Khoa, ĐHQG-HCM
}

TÓM TÄT: Cơ chế phát triển ống nano carbon đon thành được tổng hợp bằng thiết bị ngung tụ hoi hoá học đã được xác định. Phroong pháp phân tích bằng kính hiển vi điện tủ̉ truyền qua (TEM) đạ được sử dụng để quan sát vị trí, hình thái của các hạt xúc tác. Nghiên cưu đã xúc định được các hạt xúc tác đều được cố định ở chân của các ống nano carbon đơn thành. Đây chính là kết quả quan trọng nhất cho thấy co chế phát triển ống nano carbon đơn thành trong nghiên cứu này là co chế "phát triển tù chân". Bên cạnh đó, tù̀ kết quả TEM, hai cơ chế phát triển mới của ống nano carbon dạng bó cũng được xác định: co chế phát triển " bó song song" và co chế phát triển "bó xoắn". Nghiên cứu cũng đồng thời khẳng định các hạt xúc tác không hề tồn tại ở trong và trên đỉnh của ống nano carbon, điều này cho thấy đây là một cơ chế đặc trung cho trường hợp tổng hợp ống nano carbon bằng thiết bị ngung tu hoi hoá họ tù̀ pha hoi.

Tù khóa: Ống nano carbon đơn thành, cơ chế phát triển tù̀ gốc, kinh hiển vi điện tử truyền qua.

\section{REFERENCES}

[1]. A.-C. Dupuis, Progress in Materials Science, 50, 929-961 (2005).

[2]. Baker RTK, Catalytic growth of carbon filaments. Carbon, 27: 315-23 (1989).

[3]. Cassel AM, Raymakers A, Kong J, Dai H.,Large scale CVD synthesis of single- walled carbon nanotubes, $J$ Phys Chem B, 103:6484-92 (1999).

[4]. Dresselhaus MS, Dresselhaus G, Eklund P C, Science of Fullerenes and Carbon Nanotubes (San Diego, CA: Academic), 965 (1996).

[5]. Justin Tan Wee Khiang, Electrochemical Storage of Hydrogen Using Carbon 
Nanotubes, Faculty of Engineering, Physical Sciences and Architecture.

[6]. Pulickel M. Ajayan and Otto Z. Zhou. Applications of Carbon Nanotubes, Appl. Phys, 80, 391-425 (2001).

[7]. M. Meyyappan,Carbon nanotubes science and applications, CRC PRESS(2005).

[8]. A. Loiseau P. Launois P. Petit, S. Roche J.-P. Salvetat, Understanding Carbon Nanotubes, Springer (2006).
[9]. Dai H, Rinzler A G, Nikolaev P, Thess A, Colbert D T and Smalley R E,Single-wall nanotubes produced by metal-catalyzed disproportionation of carbon monoxide,Chem. Phys. Lett., 260, 471-5 (1996).

[10]. E.F. Kukovitsky, S.G. L’vov, N.A. Sainov, VLS-growth of carbon nanotubes from the vapor, Chemical Physics Letters, 317_2000,65-70. 